\title{
The Quality Management Model Construction of International Chinese Language Education based on TQM
}

\author{
Wu Cai \\ Overseas Education College, Xiamen University, Xiamen, China \\ totc1003@163.com
}

\begin{abstract}
With the continuous development of international Chinese language education, how to improve its quality has become a major issue. This paper describes the current development status, existing problems and development trend of international Chinese language education in accord with latest statistical records. Then the paper tends to introduce the term of Total Quality Management (TQM) and its application in education. In order to improve the teaching effects and achieve sustainable development, the author applies the Plan-Do-Check-Action (PDCA) circle to integrating TQM into international Chinese language education.
\end{abstract}

Keywords: International Chinese language education, Total Quality Management, PDCA circle, Sustainable development.

\section{Introduction}

With the rise of China's economy and global influence, more and more people begin to learn Chinese language over the past three decades. International Chinese language education has gained unprecedented growth. Most people have a positive attitude towards the development prospects of international Chinese language education. However, there are still lots of problems in the development process of international popularization of Chinese language. These problems seriously affect the spread of Chinese language and Chinese culture.

In this paper, the author will quote recent statistical records to describe the current status, existing problems and development trend of international Chinese language education. In order to achieve sustainable development of international Chinese language education, the managers and policy makers should improve its level and quality. Therefore, the principles of Total Quality Management (TQM) and its applications in education will be introduced in the paper. In the last section, the author will present the quality management model of international Chinese language education based on TQM.

\section{The Current Status, Existing Problems and Development Trend of International Chinese Language Education}

\subsection{The Current Development Status of International Chinese Language Education}

In recent years, with the rapid expansion of the global demand for Chinese language, the number of Chinese as a second language (CSL) learners has already exceeds 100 million and continues to increase all over the world. The statistics from the Confucius Institute Headquarters showed that there were more than 60 countries and regions embracing Chinese language teaching into the national education system in the world. The United States, Britain, France, Malaysia, Thailand, South Korea and other more than 170 countries have opened Chinese language courses or majors. Among these countries, the number of CSL learners in the United States has reached 2.8 million and the number of CSL learners in the UK will probably be 400,000 in 2020.

Meanwhile, according to the statistics from 2015 Confucius Institute Annual Development Report, a total of 6 million people took various kinds of Chinese tests all around the world in 2015. In the same year, 9,168 candidates, including 403 non- Chinese candidates took the Certificate Examination for Teachers of Chinese to Speakers of other Languages. Among the candidates, 7,067 applied for written tests and 2,101 for interviews. In terms of scholarship settings, 4,289 new scholarship students from 114 countries have been enrolled by the Confucius Institute Headquarters in 2015 [1]. These statistical records fully reflect the great influence of Chinese language and culture. 
Table 1. Expenditures of Confucius Institutes (Classrooms) by Headquarters in 2015 [2]

\begin{tabular}{|c|c|c|}
\hline Number & Project Names & $\begin{array}{c}\text { Total 2015 (thousand US } \\
\text { dollar) }\end{array}$ \\
\hline 1 & Start-up funds for Confucius Institutes (Classrooms) & 6,727 \\
\hline 2 & Operational funds of Confucius Institutes(Classrooms) & 228,979 \\
\hline 3 & Confucius China Studies Program & 4,620 \\
\hline 4 & Model Confucius Institutes & 12,328 \\
\hline 5 & Trainings for directors, teachers and volunteers & 5,837 \\
\hline 6 & Confucius Institute Scholarships & 34,680 \\
\hline 7 & Operational funds for Confucius Institute Online & 6,131 \\
\hline 8 & Chinese and foreign expert lecture tours, teaching \\
& materials exhibition tours and student performance tours & 4,620 \\
\hline 9 & Development and distribution of teaching materials & 3,080 \\
\hline 10 & On-site supervision by Chinese and foreign experts & 909 \\
\hline 11 & Bilingual versions of Confucius Institute & 2,943 \\
\hline & Total & 310,854 \\
\hline
\end{tabular}

Sufficient financial support provides a solid foundation for promoting the development of international Chinese language education. From Table 1, it is clearly found that operational funds of Confucius Institutes (Classrooms) were the biggest expenditures of Confucius Institutes (Classrooms) by Headquarters in 2015. More specifically, operational funds accounted for $73.7 \%$ of the total expenditures of Confucius Institutes (Classrooms) in 2015. On the other hand, it reflects operation management is the top priority of Confucius Institute (Classrooms) at present.

Additionally, with continuous economic development and the influence expansion of Chinese language, China has become a major destination in the global market for international students [3]. After collecting and analyzing data from the annual China releases report on foreign students in the website of China's Ministry of Education [4], it was found that the number of different kinds of foreign students is 292,611, 328,330, 356,499, 377,054 and 397,635 from 2011 to 2015 respectively. Furthermore, the average annual growth rate of the number of foreign students in China is $7.97 \%$ during the five years. Among these foreign students in China, quite a few students come to learn Chinese language and culture.

\subsection{The Existing Problems of International Chinese Language Education}

China has made significant progress in international Chinese language education in the recent years. Nevertheless, many problems which may threaten the sustainable growth of international Chinese language education still exist in the process of its development. For instance, Li and Wang announced there was a shortage of qualified teachers, appropriate teaching methods and suitable teaching materials to meet the needs of providing enough teaching and learning resources and services to CSL learners [5]. Wu and $\mathrm{Ti}$ also put forwards that even though Confucius Institute has enjoyed a rapid development and brought a great deal of international influence, it still needed to make a significant breakthrough in the training of CSL teachers, teaching methods and teaching materials [6]. Wu pointed out that the problems appeared as the shortage of teachers, teaching materials and proper teaching methods in the development process of international Chinese language education all around the world too [7].

Some scholars suggested that take measures to deal with them. For example, Cai expressed his opinion of integrating the framework of TPACK (technological pedagogical and content knowledge) into CSL teacher training [8]. With the extensive development of international promotion of Chinese language, the new elements should be added into teaching materials of teaching Chinese as a second language. Adding the cultural diversity in the teaching materials to create conditions for inter-cultural communication can be appropriate considered [9]. The application of mobile technology can bring more learning resources and learning styles to CSL learners in different ways within a real social context. This will be the future development direction of teaching methods in the practice of teaching Chinese as a second language [10]. 
The lack of qualified teachers, appropriate teaching methods and suitable teaching materials reveals teaching quality and effects need to be improved in the international Chinese language education. Actually, the excellent teaching quality is the important guarantee of international Chinese language education. Improving quality will play a key role in the educational planning and administration of international Chinese language popularization.

\subsection{The Development Trend of International Chinese Language Education}

In recent years, the industrial characteristics of language education have become increasingly prominent, and gradually received attention by more and more scholars. It is even regarded as a new growth point to promote the national or regional economy. From the perspective of economics, language education is both business and industry. Many facts have proven that language education industry can bring considerable economic benefits. For instance, The UK receives a large amount of tax revenue from English textbooks and related fields each year. The estimated value of the language industry within the European Member States was around 8.5 billion euros in 2008. More specifically, the translation and interpreting sector comprising soft localization and website globalization activities accounted for 5.68 billion euros. Language teaching accounted for 1.579 billion euros. Multilingual support within conference organization accounted for 143 million euros. The sector subtitling and dubbing accounted for 633 million. The sector of language technology tools was estimated at 568 million [11].

Language education could be divided into the cause and the industry. As a cause, language education which needs financial support and involves a lot of economic issues. On the other hand, the language education industry contains a large number of economic activities [12]. In China, the output value of Chinese language industry is equally impressive. Chen revealed that the total output value of the language industry is 192 billion yuan in China in 2010, which accounted for $0.47 \%$ of GDP in China that year [13]. There is no doubt that the economic contribution of language industry in China will be gradually increasing in the future.

Therefore, it means language education itself has the characteristics of industry and is also an important part of international education services. It can bring considerable economic benefits and international influence. In this specific context, enhancing further ahead in the degree of integration between production and education will be the development trend of international Chinese language education. It is necessary to give full play to the competitive advantage of the global Chinese language education market, encourage the entry of private capital, and form a flexible industrial operation mechanism under the premise of respecting the laws of education.

\section{Discussion of Integrating Total Quality Management into International Chinese Language Education}

\subsection{Total Quality Management}

The latest development statistics of international Chinese language education reveal the current status, existing problems and development trend of it. In the present complicated educational situation, improving quality of international Chinese language education appears particularly important. The author attempts to use the principles of Total Quality Management to construct a quality management model of international Chinese language education.

It is difficult to illustrate the exact date of birth of the concept of Total Quality Management. In fact, many of the factors of TQM were formed during the 1950s to 1970s, however, until in the second half of the 1980, the concept of TQM began to be popularized in the world [14]. Specifically, the origins of TQM can be traced to 1949 when the Japanese improved their economy and industry, enhanced the quality of their lives and gained great development through an amazing management strategy [15]. In 1961, Feigenbaum firstly introduced the term of Total Quality Control as "an effective system for integrating the quality development, quality maintenance, and quality-improvement efforts of the various groups in an organization so as to enable production and service at the most economical levels which allow for full customer satisfaction" [16].

Since the late 1980s, Total Quality Management gradually evolved from the early Total Quality Control. The core factors of TQM can be summed up as "three full" and "four all". The concept of 
"three full" means the overall quality, the whole process and the management participated by all personnel. "Four all" refers to all for the sake of customers, all based on prevention, all the work with data to speak and all the work carried out by the Plan- Do-Check -Action (PDCA) cycle [17].

\subsection{The Application of TQM in Education}

Nowadays the concept of TQM is not only limited to business sector or manufacturing industry in the world. Sakthivel and Raju pointed out it had been successfully applied in the field of education in the developed countries such as the USA and UK [18]. They sorted out the views of different scholars about TQM. For example, TQM is a great approach to achieve and maintain excellence in higher education. TQM is also an integrated management system that focuses on fulfill the satisfaction of customers and seeks continuous improvement of processes. These opinions are the advantages of applying TQM in the field of education.

In addition, TQM can provide an excellent environment for innovation. Prajogo and Sohal put forward that there was a significant relationship between TQM practices and innovation performance [19]. Therefore, embracing TQM is beneficial to the educators to enhance innovation performance in education. From the perspectives of optimization of the activity of faculties, vertical alignment, horizontal alignment and a single command for all activities, Militarua, Ungureanua and Chenic also explored the differences between an university which had been organized according to the principles of TQM and an ordinary one which was not be organized by TQM [20] .

In a word, TQM plays an important part in promoting the efficiency of the teachers and educational institutions' administrators. It will be helpful to improve learning outcomes of learners and teaching quality. But it should be noted that the educators must take into account the actual situation they face when applying TQM into education.

\subsection{Integrating Total Quality Management into International Chinese Language Education}

After a lot of theoretical exploration and practice, the application of TQM in Education has become more and more mature and popular. The mode of Total Quality Management is not only conducive to the effective and rapid promotion of Chinese language and Chinese culture, but also beneficial to the sustainable development of educational institutions which promote International Chinese language education. The author will apply the cycle of Plan-Do-Check-Action (PDCA) to integrating Total Quality Management into international Chinese language education. The PDCA management cycle is not only a kind of scientific management, but also a fundamental section for TQM. The author believes that the PDCA management circle can be applied successfully in international Chinese language education.

1) Plan

Nothing can be accomplished without norms or standards. Before the teaching activities, all the staff in the Chinese language educational institutions, including the leaders, administrators and teachers should gather together to set quality evaluation standard of international Chinese language education. Using the evaluation standard, it will be easier for all the staff to have a big picture of the teaching quality. However, it is worth noting that the CSL learners are the customers in the international Chinese language education from TQM perspective. Therefore, the needs and feelings of CSL learners are most important. In other words, the satisfaction of CSL learners should be firstly taken into account in the plan.

2) Do

Once the quality evaluation norms or standards are established, all the staff must effectively implement them. They should pay attention to the quality of international Chinese language education and try their best to overcome the problems which have mentioned before in the paper. For instance, the leaders should increase the input and sources of funds and train excellent Chinese teachers as much as possible. The teachers should strive to improve their own teaching abilities and master more teaching methods. The teaching materials editors should design teaching material to satisfy the CSL learners' needs. In order to achieve the desired learning outcomes, appropriate training can be carried out according to actual need.

3) Check 
All the staff should collect sufficient and accurate statistics in the process of teaching and check whether the implementation of the results meet the preset goals carefully. All the staff should have an overall view of what they do. Each staff not only inspects the work within his or her scope, but also helps others to check and try the best to find out the problems. Whether or not to find the problem, a good job of prevention must be prepared as soon as possible. For example, whether the CSL learners master the basic knowledge of Chinese, such as Chinese characters, vocabulary, grammar and pronunciation needs to be checked. Whether the CSL learners master the skills of Chinese listening, speaking, reading and writing needs to be checked. Whether the CSL learners master the communicative competence in the real life situation needs be checked too.

4) Action

After careful checking, if there are any problems, related responsible person should take measures to resolve problems in a timely manner. In order to gain the best effect, it is necessary to build teaching quality monitoring system in multi-channels. It will be useful to master relevant information and deal with problems in the fastest time. For instance, if the teaching goals are not achieved, the teachers should reflective their teaching process and analyze the reasons for making the mistakes. Then the specific solutions will be proposed. If the CSL learners do not have enough Chinese communication competence, the teachers should create more and more communication opportunities. The learning process can be significantly richer when CSL learners have access to a wide variety of useful learning channels and resources.

\section{Conclusions}

In recent years, it is an important historic stage in the development of international Chinese language education. The author quotes a great deal of recent statistical records to show the current development status, existing problems and development trend of international Chinese language education. Then the concept of Total Quality Management and its application in education are introduced in the paper. It is of great significance for the quality management of international Chinese language education. In the last sector, the author applies the cycle of PDCA to integrate Total Quality Management into international Chinese language education.

It can be believed that the quality management model based on TQM will be helpful to improve the teaching effects and achieve sustainable development of international Chinese language education. Through this paper, the author also would like to encourage the managers and policy makers of international Chinese language education to pay attention to implement teaching quality management.

\section{Reference}

[1] L. Xu, J.F. Ma, et al.: 2015 Confucius Institute Annual Development Report, p.7 (Confucius Institute Headquarters (Hanban), Beijing 2015)

[2] L. Xu, J.F. Ma, et al.: 2015 Confucius Institute Annual Development Report, p. 44-45 (Confucius Institute Headquarters (Hanban), Beijing 2015),

[3] X.J. Ding: Exploring the Experiences of International Students in China, Journal of Studies in International Education, Vol. 20 No.4 (2016), p. 319-338

[4] Information on http://en.moe.gov.cn/

[5] S. Li and J.Q. Wang: Chinese Government Policies and Initiatives on the International Popularization of Chinese: An Economics of Language Perspective, in: Chinese Language Education in the United States, edited by J.N. Ruan, J. Zhang and C.B. Leung, Volume 14 of the series Multilingual Education, chapter, 2, p.29-45, (Springer International Publishing, Switzerland 2016) 
[6] Y. Wu and W.J. Ti: The Development Status and Problems of Confucius Institute, Journal of Yunnan Normal University (Teaching and Research on Chinese as a Foreign Language), Vol. 7 No.5 (2009), p.28-33 (In Chinese)

[7] Y.H. Wu: On the Fundamental Problems and Strategies of Heritage Chinese Education in Southeast Asia, Journal of Zhejiang Normal University ( Social Sciences), Vol. 41 No.1(2016), p.8-13 (In Chinese)

[8] W. Cai: TPACK: A New Dimension to Chinese as a Second Language Teacher Training, Proceedings of the 2016 2nd International Conference on Social Science and Higher Education (ICSSHE 2016), Advances in Social Science, Education and Humanities Research, Vol. 53, p. $460-465$

[9] Y.M. Wang: The Innovation of Textbooks in Teaching Chinese as a Foreign Language, Language Teaching and Linguistic Studies, No.4 (2004) , p. 78-82

[10] W. Cai: The Study of Teaching Chinese as a Second Language Based on Mobile Assisted Language Learning, Proceedings of the 6th International Conference on Electronic, Mechanical, Information and Management Society (EMIM 2016), Advances in Computer Science Research, Vol. 40, p.575-580

[11]A. Rinsche and N. Portera-Zanotti: Studies on Translation and Multilingualism: The Size of the Language Industry in the EU, European Commission, Directorate-General for Translation, 2009

[12] Y.M. Li: Understanding the Economic Attributes of Language, Applied Linguistics, No.3(2012), p.2-8 (In Chinese)

[13] P. Chen: Some Issues on the Economic Contribution of Language Industry, Applied Linguistics, No. 3(2016), p.86-93 (In Chinese)

[14] A.R. Martínez-Lorente, F. Ewhurst and B. G. Dale: Total quality management: origins and evolution of the term, The TQM Magazine, Vol.10 Iss.5 (1998), p. 378 - 386

[15] T.C. Powell: Total Quality Management as Competitive Advantage: A Review and Empirical Study, Strategic Management Journal, Vol.16 No. 1 (1995), p. 15-37

[16] A.V. Feigenbaum (1961), Total Quality Control, McGrawHill, New York.

[17] F. Wang: The Construction of Teaching Quality Monitoring System Based On TQM of Chinese Application Technology University, 2014 2nd International Conference on Economic, Business Management and Education Innovation (EBMEI 2014), Lecture Notes in Management Science, Vol. 39(2014), p.169-173

[18] P. B. Sakthivel and R. Raju: Conceptualizing total quality management in engineering education and developing a TQM educational excellence model, Total Quality Management \& Business Excellence, 17:7(2006), p. 913-934

[19] D.I. Prajogo, A.S. Sohal: TQM and innovation: a literature review and research framework, Technovation 21 (2001), p. 539-558

[20] M. Militarua, G. Ungureanua and A. Ş. Chenic: The prospects of implementing the principles of Total Quality Management (TQM) in education, 3rd World Conference on Learning, Teaching and Educational Leadership, Procedia - Social and Behavioral Sciences, Vol. 93 (2013), p. 1138-1141 